\title{
Space charge fields in DC cables
}

\section{McAllister, lain Wilson; Crichton, George C; Pedersen, Aage}

\section{Published in:}

Conference Record of the IEEE International Symposium on Electrical Insulation

Link to article, DOI:

10.1109/ELINSL.1996.549432

Publication date:

1996

\section{Document Version}

Publisher's PDF, also known as Version of record

Link back to DTU Orbit

Citation (APA):

McAllister, I. W., Crichton, G. C., \& Pedersen, A. (1996). Space charge fields in DC cables. In Conference Record of the IEEE International Symposium on Electrical Insulation (Vol. Volume 2, pp. 661-665). IEEE. https://doi.org/10.1109/ELINSL.1996.549432

\section{General rights}

Copyright and moral rights for the publications made accessible in the public portal are retained by the authors and/or other copyright owners and it is a condition of accessing publications that users recognise and abide by the legal requirements associated with these rights.

- Users may download and print one copy of any publication from the public portal for the purpose of private study or research.

- You may not further distribute the material or use it for any profit-making activity or commercial gain

- You may freely distribute the URL identifying the publication in the public portal

If you believe that this document breaches copyright please contact us providing details, and we will remove access to the work immediately and investigate your claim 
Conference Record of the 1996 IEEE International Symposium on Electrical Insulation, Montreal, Quebec, Canada, June 16-19, 1996

Space Charge Fields in DC Cables

\author{
I.W. McAllister, G.C. Crichton and A. Pedersent \\ Department of Electric Power Engineering Department of Physics \\ Building 325 \\ Technical University of Denmark \\ DK-2800 Lyngby, Denmark
}

\begin{abstract}
The space charge that accumulates in DC cables can, mathematically, be resolved into two components. One is related to the temperature and the other to the magnitude of the electric field strength. Analytical expressions for the electric fields arising from each of these space charge components are deri.ved. Thereafter, the significance of these field components under both normal operating conditions and immedistely following polarity reversal is discussed.
\end{abstract}

\section{INTRODUCTION}

Previously, the authors have shown that the accumulation of space charge in $D C$ cable insulation is an inherent phenomenon [1]. The presence of such space charge in the bulk of the dielectric constrains the field to be poissonian. The corresponding field strength $\vec{E}$ can thus be expressed as

$\vec{E}=\overrightarrow{E_{L}}+\delta \vec{E}$

where $\overrightarrow{E_{L}}$ represents the basic Laplace field [2] associated with the applied voltage $U$, and $\delta \vec{E}$ represents the basic Poisson field [2]. This latter component is established by the space charges in the dielectric together with the associated Poissonian induced charges [3] on the electrodes.

Traditionally, electric fields associated with DC cables are evaluated
directly using the functional dependence of the insulation conductivity on

$\uparrow$ deceased temperature and field strength. This circuit theory approach is used in many papers and textbooks on cable technology. In the present study, analytical expressions for the electric field are derived from a knowledge of the inherent space charge distribution: i.e. a field theoretical approach is adopted. This

approach allows the significance of $\delta \vec{E}$ under steady-state operation and for conditions immediately following polarity reversal to be discussed in depth.

\section{SPACE CHARGE IN THE INSULATION}

Consider a coaxial cable insulated with a macroscopically homogeneous dielectric of constant permittivity. The conductivity $\gamma$ of this dielectric is a function of both the temperature $T$ and the magnitude of the electric field strength $|E|$. In this study, the $y$ dependence is represented by an empirical relationship which is valid over the practical range of $T$ and $|E|[4]$; viz.

$\gamma=\gamma_{a}\left(|E| /\left|E_{a}\right|\right)^{\nu} \exp \left[\alpha\left(T-T_{a}\right)\right]$

where $\gamma_{a}$ is the conductivity for a reference field strength $E_{a}$ and temperature $T_{a}$. The parameter $\nu$ is a material constant which for oilimpregnated paper is approximately zero, but which for polyethylene can be ascribed values in the range 2.1 to 2.4 [4]: $\alpha$ is a constant and for the dielectrics used in cables the value 0.1 $\mathrm{K}^{-1}$ is appropriate.

For a loaded DC cable, which is in 
thermal equilibrium, it has been shown in [1] that the space charge density $\rho$ may mathematically be considered as the sum of two components:

$\rho=\rho_{T}+\rho|E|$

where $\rho_{T}$ is the component associated with temperature while $P|E|$ is that related to the magnitude of the electric field strength. In [1] expressions were derived for these components: viz.

$\rho_{T}=\frac{\varepsilon k \beta U}{a^{2}} \frac{(r / a)^{k-2}}{(b / a)^{k}-1}$

$P|E|=\frac{\varepsilon k(k-\beta) U}{a^{2}} \frac{(r / a)^{k-2}}{(b / a)^{k}-1}$

where $a$ and $b$ are the inner and outer radii of the dielectric, and $r$ is a cylindrical coordinate. $U$ represents the applied DC voltage while $k$ and $\beta$ are dimensionless parameters given by

$k=\frac{\nu+\beta}{\nu+1}$

$\beta=\alpha\left(T_{a}-T_{b}\right) / \ln (b / a)$

$T_{a}$ and $T_{b}$ are the temperatures at distances $a$ and $b$ from the cable axis. From (3), (4) and (5) it is evident that

$\rho=\frac{\varepsilon k^{2} U}{a^{2}} \frac{(r / a)^{k-2}}{(b / a)^{k}-1}$

and thus $\rho_{T}$ and $\rho_{\mid E} \mid$ may be simply expressed in terms of $\rho$ : viz.

$\rho_{T}=(\beta / k) \rho$

$\rho_{|E|}=(1-\beta / k) \rho$

\section{FIELD SOURCES Insulation Space Charge}

In evaluating the field distribution as a function of the radial distance $r$, it is necessary to refer to the total charge $Q$ per unit length enclosed within a cylindrical shell of thickness $(r-a)$ :

$Q=\int_{a}^{r} \rho 2 \pi r^{\prime} \mathrm{d} r^{\prime}$

where $r^{\prime}$ is a dummy variable, Upon substitution for $\rho,(8)$, and integrating we obtain

$Q=2 \pi \varepsilon k U \frac{(r / a)^{k}-1}{(b / a)^{k}-1}$

Hence on the basis of (4) and (5) we arrive at the simple relationships

$Q_{T}=(\beta / k) Q$

$Q_{|E|}=(1-\beta / k) Q$

\section{Charge Induced by the Space Charge}

For the volume space charge distribution, the Poissonian induced charge $q$ may be expressed as [2]

$q=-\int \lambda(r) \rho \mathrm{d} \Omega$

where $d \Omega$ is a volume element. The parameter $\lambda$ is the proportionality factor between the space charge accumulated in the insulation and the charge induced on the conductor in question. The $\lambda$-function is a solution of the general Laplace equation [2]

$\vec{\nabla} \cdot(\varepsilon \vec{\nabla} \lambda)=0$

in which $\varepsilon$ denotes permittivity. The relevant boundary conditions are $\lambda=1$ for $r=a$ and $\lambda=0$ for $r=b$. For the present simple case of the coaxial geometry with a homogeneous dielectric, the appropriate solution of Laplace's equation for the $\lambda$-function is

$\lambda=1-\frac{\ln (r / a)}{\ln (b / a)}$

Owing to the axial symmetry of the space charge distribution, it is however more appropriate to consider $q$ as the charge induced per unit length. Hence for a cylindrical shell of radius $r$ and 
thickness $\mathrm{d} r$ we have

$q=-\int_{a}^{b} \lambda \rho 2 \pi r d r$

Upon combining (17) with (8) integrating, we can express $q$ as

$q=2 \pi \varepsilon k U\left[1-\frac{(b / a)^{k}-1}{k \ln (b / a)}\right]$

The components of $q$ follow directly: viz.

$q_{T}=(\beta / k) q$

$q_{|E|}=(1-\beta / k) q$

As the induced charge is of opposite polarity to the source charge, see (18), this implies that the field components associated with $Q$ and $q$ are in opposition.

\section{ELECTRIC FIELDS}

In view of the symmetry of the space charge distribution, the basic Poisson field strength $\delta E$ at a distance $r$ is given by

$\delta E=\frac{Q+q}{2 \pi \varepsilon r}$

Owing to symmetry, all vector quantities will be directed either radially away from or towards the axis. We can therefore replace all vector equations with scalar equations. The direction of the field is away from the axis for $E$ positive. Upon introducing (12) and (19) into (22), we obtain

$\delta E=\frac{U}{r \ln (b / a)}\left[\frac{k \ln (b / a)}{(b / a)^{k}-1}(r / a)^{k}-1\right]$

and the associated components of $\delta E$ are

$\delta E_{T}=(\beta / k) \delta E$

$\delta E_{|E|}=(1-\beta / k) \delta E$
For the coaxial geometry, the basic Laplace field is simply given by

$E_{\mathrm{L}}=\frac{U}{r \ln (b / a)}$

Thus on the basis of (1), the net steady state field $E$ can be expressed as

$E=\frac{U}{a} \frac{k(r / a)^{k-1}}{(b / a)^{k}-1}$

It should be noted that this field expression is identical with that derived in [4] using the traditional approach.

The reversal of the applied voltage polarity can occur on a time-scale which is very short in comparison to the relaxation time constant associated with the accumulation of space charge in the cable insulation. Thus, immediately following such a reversal of polarity, the magnitude and distribution of the space charges are virtually unaffected. Consequently, although the basic Laplace field has changed polarity, the basic Poisson field is effectively unchanged. Hence following polarity reversal, the initial field $E_{\mathrm{R}}$ may be expressed as

$$
E_{\mathrm{R}}=-\frac{U}{a}\left[\frac{2}{(r / a) \ln (b / a)}-\frac{k(r / a)^{k-1}}{(b / a)^{k}-1}\right]
$$

\section{APPLICATION OF THEORY}

To illustrate the order of magnitude of the effects of the accumulated space charge in a coaxial DC cable, we consider the $250 \mathrm{kV}$, $500 \mathrm{MW}$ XLPE cable proposed by Fukagawa et al. [5]. As $\nu$ can attain values between 2.1 and 2.4 , we assume for expediency a value of 2.25 . The parameter $\beta$ can be evaluated if the power dissipated in the conductor per unit length $P_{c}$ is known [1]. The relationship is

$\beta=\frac{\alpha P_{C}}{2 \pi \kappa}$

We assume that the temperature of the conductor has the specified maximum value of $80^{\circ} \mathrm{C}$, and that the thermal 
conductivity $\kappa$ of XLPE is $0.3 \mathrm{~W} / \mathrm{Km}$. Thereafter, on the basis of the data given in [5], we obtain $\beta=4.53$.

Using (6), (8), (9) and (10), the radial variations of $\rho, \rho_{T}$ and $\rho|E|^{\text {were }}$ derived. Results are shown in Figure 1, in which $x$ is the radial distance from the surface of the inner conductor; i.e. $x=r-a$. On letting $d$ denote the insulation thickness, we have $d=b-a$. From Figure 1 , it is evident that the space charge distributions are only slightly non-uniform in that these distributions deviate by $<5 \%$ from their average values. Moreover $\left|\rho_{T}\right|$ attains values of about twice $|\rho| E||$. However, as these components are of opposite polarity, the net space charge $\rho$ is about $\left(\rho_{T} / 2\right)$ such that $\rho$ lies in the range of $12<\rho /\left(\mathrm{pC} / \mathrm{mm}^{3}\right) \leq 13$.

The electric fields associated with the space charge were evaluated using (6)

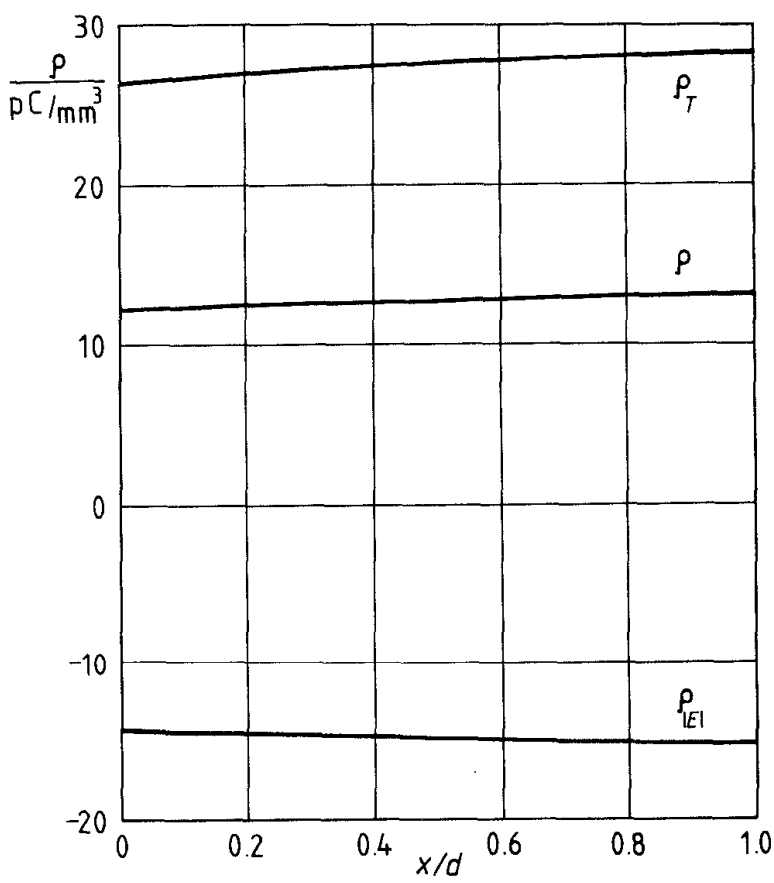

Figure 1. Radial variation of space charge $\rho$ and its components in a loaded DC cable.
(23) to (27) and (29) and the results are illustrated in Figure 2. The behaviour of $\delta E, \delta E_{T}$ and $\delta E_{|E|}$ can be understood with reference to the corresponding space charge distributions, where we recall that the induced charge is of opposite polarity to the space charge. As a consequence of this latter feature, the values of $\delta E, \delta E_{T}$ and $\delta E_{|E|}$ are zero for $(r / a)=\left[\frac{(b / a)^{k}-1}{k \ln (b / a)}\right]^{1 / k}$

see (23). With respect to Figure 2, we have the relationship

$(x / d)=\frac{(r / a)-1}{(b / a)-1}$

Upon using the present values of $k$ and $(b / a)$, we find that $(x / d)_{0}=0.47$, see Figure 2. As a result of the space charge field $\delta E$ changing polarity at $(x / d)_{0}$, this field opposes $E_{L}$ for $(x / d)<(x / d)_{0}$,

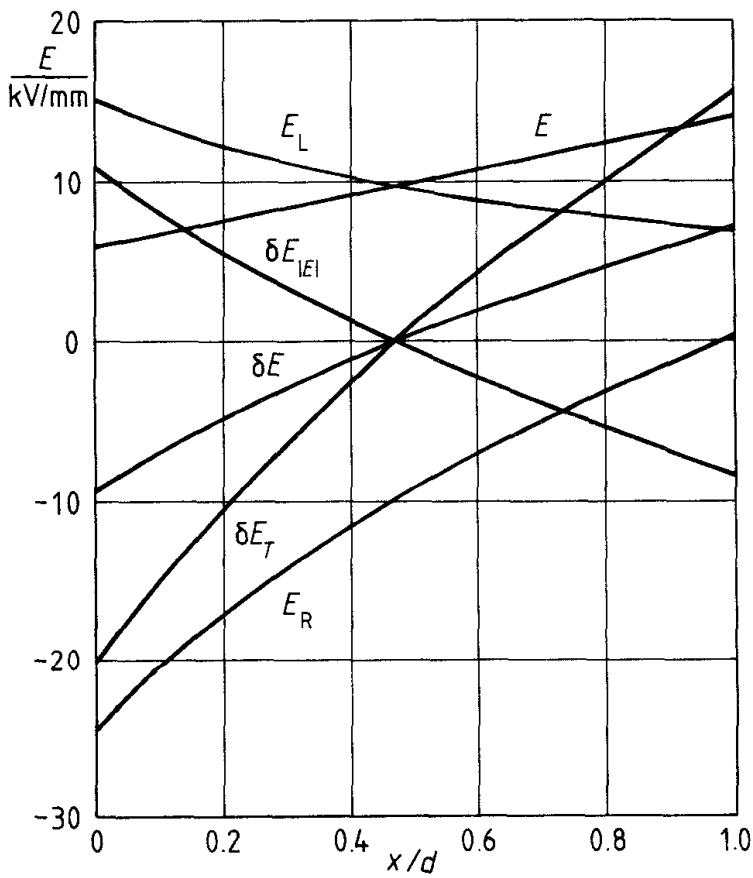

Figure 2. Radial variation of electric field distributions $E$ in a loaded DC cable. 
whereas $\delta E$ augments $E_{L}$ for $(x / d)>(x / d)_{0}$ such that we obtain stress inversion: i.e. the greatest stress now occurs at the cable sheath.

For the present $\nu$ and $\beta$ values, the exponent of the radial distance, $(k-1)$, is 1.08 . As a result, the steady-state field $E$ varies essentially linearly with the radial distance. Following polarity reversal, the magnitude of the field at the inner conductor is seen to be increased by $61 \%$ above that of $E_{L}$, see Figure 2 .

\section{CONCLUSION}

From a knowledge of the inherent space charge distribution in a DC cable, it is possible to identify the influence upon the electric field distribution of the parameters which control the insulation conductivity. For a loaded cable, it is shown that the major influence on the field distribution is associated with temperature, although this is seen to be counteracted partially by that of the electric field. This behaviour suggests that the conductivity parameters coldd be selected such as to minimise the resultant space-charge-generated electric field. Such an approach would reduce overstressing of the insulation which otherwise would certainly be encountered on polarity reversal.

\section{REFERENCES}

1. McAllister, I.W., G.C. Crichton and A. Pedersen. "Charge Accumulation in DC Cables: A Macroscopic Approach". Conference Record of the 1994 IEEE International Symposium on Electrical Insulation. IEEE Publication 94CH3445-4, 1994, pp.212216.

2. Pedersen, A., G.C. Crichton and I.W. McAllister. "The Functional Relation between Partial Discharges and Induced Charge" "IEEE Trans. Dielect. \& Elect. Insul., vol.2, 1995, pp.535-543.

3. Pedersen, A., G.C. Crichton and I.W. McAllister. "Partial Discharge Detection: Theoretical and Practical Aspects". IEE Proc. - Science, Measurement and Technology, vol.142, 1995, pp.29-36.

4. Privezentsev, V., I. Grodnev, S. Kholodny and I. Ryazanov. Fundamentals of Cable Engineering. Mir Publishers, 1973.

5. Fukagawa, H., H. Miyauchi, Y. Yamada, S. Yoshida and N. Ando. "Insulation Properties of $250 \mathrm{kV}$ DC XLPE Cables". IEEE Trans. Power Appar. \& Syst., vol.PAS-100, 1981, pp.3175-3184. 